\title{
Emerging Scholar Best Article Award, 2012
}

\author{
Roger J. R. Levesque
}

Received: 6 August 2012/Accepted: 8 August 2012/Published online: 22 August 2012

(C) Springer Science+Business Media, LLC 2012

The Journal of Youth and Adolescence continues its distinguished history of supporting emerging scholars by conferring its Emerging Scholar Best Article Award (see Levesque 2011). To be eligible for the award, the article's first author must be an "emerging scholar," which we interpret as being non-tenured (e.g., a graduate student, post-doctoral scholar, research scientist, or assistant professor). A random group of editorial board members (with potential recipients excluded) select the recipient. The winner receives a plaque as well as a small financial award generously provided by Springer, the journal's publisher.

The 2012 winner is Eeske van Roekel, for her article entitled "Parental Depressive Feelings, Parental Support, and the Serotonin Transporter Gene as Predictors of Adolescent Depressive Feelings: A Latent Growth Curve Analysis" (van Roekel et al. 2011). Given that the journal publishes 12 issues per year, each containing at least 10 manuscripts, the editors view the award as a considerably distinctive accomplishment. The "best" article for 2011 was selected from a large pool of very strong articles, 13 (there was a tie for manuscripts appearing in one of the issues). As we have done in the past, we like to review briefly these articles to highlight their competitiveness as well as showcase the type of research being conducted by the next generation of researchers studying the adolescent period.

The final pool of articles included ten that the editors viewed as very strong and worthy of recognition. Zona and

Roger J. R. Levesque serves as Editor of the Journal of Youth and Adolescence and is Professor of Criminal Justice, Indiana University.

R. J. R. Levesque ( $₫)$

Indiana University, 302 Sycamore Hall, Bloomington, IN, USA

e-mail: rlevesqu@indiana.edu
Milan (2011) examined the moderating effects of gender on the longitudinal association between exposure to violence and a variety of mental health symptoms (externalizing, internalizing, PTSD, dissociation) in a racially diverse urban adolescent sample ( $\mathrm{N}=615 ; 50.6 \%$ female). They found that, although boys reported more exposure to violence on average, girls experiencing violence were more likely to experience dissociative (but not PTSD, internalizing, or externalizing) symptoms. They concluded that adolescent girls may be especially vulnerable to experiencing certain trauma-related symptoms and that there may exist genderspecific pathways to trauma-related psychopathology. Dotterer and Lowe (2011) tested whether school engagement mediated the link between classroom context and academic achievement among 5th grade students, and whether these pathways were the same for students with previous achievement difficulties identified in 3rd grade. Participants included 1,014 children (50\% female) in 5th grade (mean age $=11$ ). Their results suggested that improving classroom quality may not be sufficient to improve student engagement and that additional strategies may be needed to increase the achievement for students with previous achievement difficulties. Raynolds and Juvonen (2011) assessed whether early maturation is linked with perceived popularity and/or rumors, and whether these reputational factors help account for earlier maturing girls' vulnerability to emotional distress. Drawing on three waves of data collected from an ethnically diverse sample of middle school girls $(\mathrm{n}=912)$, they found, for example, that more advanced development at the start of middle school predicted peer- and teacher-reported popularity as well as increased risk of being targeted for rumors; and they also found, in turn, that rumors acted as a partial mechanism through which early maturation was associated with subsequent internalizing symptoms. Negriff et al. (2011) examined longitudinal models incorporating pubertal 
timing, delinquency, and sexual activity in a sample of 454 adolescents (9-13 years old at enrollment; $47 \%$ females). Results revealed that early pubertal timing at Time 1 was related to more sexual activity at Time 2 , which was related to higher delinquency at Time 3 . They also importantly found that friendship variables did not mediate these associations, that neither gender nor maltreatment status moderated the meditational pathways, and that sexual activity preceded increases in delinquency. They concluded that early maturing adolescents may actively seek out opportunities to engage in sexual activity, which appears to be a risk factor for subsequent delinquency. Petrin et al. (2011) explored relationships between perceptions of community and residential aspirations to high school risk and competence status in an ethnically diverse sample of 8,754 rural adolescents (51.5\% female). Participants were from 73 rural high schools across 34 states. High competence students (i.e., those in configurations of high positive and low negative teacher-rated characteristics) expressed positive perceptions of their rural lifestyle and many, particularly girls, indicated an interest in staying in or returning to their home community; low competence youth (i.e., those in configurations of low positive and high negative teacher-rated characteristics) appeared to be less connected to their community and were more likely to express their intent to leave and not return. Their results qualified current concerns about "rural brain drain" and suggested that the lack of attachment to the community may be a compounding risk factor for rural adolescents who have significant school adjustment problems. Bellmore et al. (2011) examined middle school transitions and the extent to which the maintenance, attainment, and loss of a cool status over the course of the sixth grade associated with student and classroom levels of physical, verbal, and relational aggression. They studied a sample of 1985 (55\% girls) ethnically diverse adolescents from 99 sixth grade classrooms in the United States. They found that attaining a cool status at any point across the school year was associated with stronger aggressive reputations. They also found that students who maintained their coolness across the school year showed greater increases in their verbally aggressive reputations from fall to spring when they were in classrooms with higher levels of aggression. Benner (2011) conducted a longitudinal study of Latino adolescents' feelings of loneliness and the repercussions of loneliness for later educational success. Participants were 640 Latino students (56\% girls, $62 \%$ Mexican/Mexican-American) who reported on loneliness across the first 2 years of high school. Growth mixture modeling identified three distinct loneliness trajectory classes for the Latino adolescents-consistently low, chronically high, and low but increasing. Language brokering, language use, and school mobility emerged as predictors of class membership. Increasingly and chronically lonely youth experienced academic difficulty, both in terms of academic progress and exit exam success, but support from friends served as a buffer of the negative relationship between loneliness and academic success. Her study highlighted the pernicious effects of loneliness and suggested promoting prosocial friendship support as a means of facilitating more positive academic outcomes for Latino youth. Stoddard et al. (2011) provided a longitudinal examination of youth living in impoverished urban neighborhoods and their sense of hopelessness about their future and engaging in violent behaviors. Using a sample of 723 (49\% female) African American youth, they found two hopelessness trajectory classes for both boys and girls during middle adolescence: a consistently low hopelessness class and an increasingly hopeless class. They also found that, in all classes, youth who reported stronger early adolescent connections to their mothers were less hopeless at age 13 and found other factors that held implications for new avenues of research and design of hope-based prevention interventions. Copeland-Linder et al. (2011) investigated the longitudinal association between contextual stress and health risk behaviors and the role of protective factors in a community epidemiologically-defined sample of urban African American adolescents $(\mathrm{N}=500 ; 46.4 \%$ female $)$. Their model found that contextual stress (community violence, neighborhood disorder, and experiences with racial discrimination) in 8th grade associated with aggressive behavior and substance use 2 years later for boys while, for girls, contextual stress predicted later substance use, but not aggressive behavior. They also found that high academic competence and self-worth reduced the impact of contextual stress on substance use only for boys. Lastly, Lee et al. (2011) examined how delinquent youths' perceptions of police legitimacy and levels of legal cynicism related to the processes of ethnic identity development. Participants were 561 black youth ages 14-18 (12\% female) who were adjudicated of a felony or serious misdemeanor and interviewed over 3 years. Their study concluded that ethnic identity development operates similarly among high risk youth as in nondelinquent samples and that it is connected to beliefs that can have implications for juvenile offenders' future compliance with the law.

Although the above articles were deemed quite strong, editorial board members ranked two others somewhat more highly. We originally had no intention of recognizing semi-finalists, but the reality is that these two may be considered as such. Indeed, each one was ranked at the top by at least one board member. Vrangalova et al. (2011) investigated controversial links between adolescent sexual activity and psychological well-being. Their study focused on the association between three aspects of teenage sexuality (genital sexual experience, age of sexual onset, and number of sex partners) and positive well-being (hedonic, eudaimonic, and overall) in a sample of 475 high school seniors (48\% female; $89 \%$ White) from a school district in a rural 
upstate New York community. They found, as they had expected, that sexually experienced and on-time (at age 16) students reported higher well-being than sexually inexperienced or lateonset (17 or older) students. Contrary to expectations, however, a high number of sex partners and an early sexual onset (15 or younger) were not related to lower well-being. Early-onset girls reported higher levels of well-being than normative-onset peers. The authors' findings made unique contributions to theoretical perspectives that center on understanding the risk versus developmental aspects of teenage sexuality. Williford et al. (2011) examined the transition from childhood and elementary school to early adolescence and middle school, as they focus on the transitions' apparent association with increases in aggressive behavior and peer victimization. To do so, they conducted latent class analyses (LCA) on rich longitudinal data $(\mathrm{N}=458$; Girls $=53 \%$; Latino $/ \mathrm{a}=53 \% ; \mathrm{M}$ age at $\mathrm{t} 1=10.2$ years). They found that elementary school students in the fourth grade initially belonged to one of four groups identified as aggressor, victim, aggressor-victim, and uninvolved latent classes. Contrary to prior research, membership in these classes changed significantly by the time students completed their first year of middle school with most youth participating in episodes of aggression and victimization during the transition. Their study was viewed as making important contributions to social dominance theory and challenging prior research that had found greater stability in aggression and victimization among early adolescents.

Finally and as noted earlier, Eeske van Roekel was the lead author of the editors' most highly regarded article published by an emerging scholar in 2011, an article that was co-authored with Rutger et al. (2011). The editors were very much impressed by the generational and genetic aspects of her study. Most notably, her study sought to understand prior inconsistent findings relating parental support and parental depressive feelings to the depressive feelings of adolescent boys and girls as well as how the 5-HTTLPR genotype interacts with environmental stressors in predicting adolescents' depressive feelings. Using five annual waves of impressive longitudinal data $(\mathrm{N}=306$; Girls $=53.3 \%$; $\mathrm{M}$ age $\mathrm{T} 1=13.4)$, she conducted latent growth curve modeling (LGCM) to examine the baseline level and change in depressive feelings over time. She found that maternal support was related to baseline levels of depressive feelings in girls, whereas paternal support was related to baseline levels in boys. Further, she found that paternal depressive feelings were only related to boys' depressive feelings at baseline, and maternal depressive feelings were not related to any outcome measures. Unlike what had been found in prior crosssectional studies, her analyses revealed no associations between 5-HTTLPR genotype and adolescent depressive feelings as well as no gene-environment interactions. I join my colleagues in congratulating Ms van Roekel, her colleagues, as well as the other authors considered for this award, for their outstanding scholarship relating to the study of adolescence and for their support of our journal.

\section{References}

Bellmore, A., Villarreal, V. M., \& Ho, A. Y. (2011). Staying cool across the first year of middle school. Journal of Youth and Adolescence, 40, 776-785. doi:10.1007/s10964-010-9590-x.

Benner, A. D. (2011). Latino adolescents' loneliness, academic performance, and the buffering nature of friendships. Journal of Youth and Adolescence, 40, 556-567. doi:10.1007/s10964-0109561-2.

Copeland-Linder, N., Lambert, S. F., Chen, Y.-F., \& Ialongo, N. S. (2011). Contextual stress and health risk behaviors among African American Adolescents. Journal of Youth and Adolescence, 40, 158-173. doi:10.1007/s10964-010-9520-y.

Dotterer, A. M., \& Lowe, K. (2011). Classroom context, school engagement, and academic achievement in early adolescence. Journal of Youth and Adolescence, 40, 1649-1660. doi: 10.1007/s10964-011-9647-5.

Lee, J. M., Steinberg, L., Piquero, A. R., \& Knight, G. P. (2011). Identity-linked perceptions of the police among African American Juvenile offenders: A developmental perspective. Journal of Youth and Adolescence, 40, 23-37. doi:10.1007/s10964-0109553-2.

Levesque, J. R. (2011). Emerging scholar best article award, 2011. Journal of Youth and Adolescence, 40, 1565-1567. doi: 10.1007/s10964-011-9721-z.

Negriff, S., Susman, E. J., \& Trickett, P. K. (2011). The developmental pathway from pubertal timing to delinquency and sexual activity from early to late adolescence. Journal of Youth and Adolescence, 40, 1343-1356. doi:10.1007/s10964-010-9621-7.

Petrin, R. A., Farmer, T. M., Meece, J. L., \& Byun, S.-Y. (2011). Interpersonal competence configurations, attachment to community, and residential aspirations of rural adolescents. Journal of Youth and Adolescence, 40, 1091-1105. doi:10.1007/s10964-011-9690-2.

Raynolds, B. M., \& Juvonen, J. (2011). The role of early maturation, perceived popularity, and rumors in the emergence of internalizing symptoms among adolescent girls. Journal of Youth and Adolescence, 40, 1407-1422. doi:10.1007/s10964-010-9619-1.

Stoddard, S. A., Henly, S. J., Sieving, R. E., \& Bolland, J. (2011). Social connections, trajectories of hopelessness, and serious violence in impoverished urban youth. Journal of Youth and Adolescence, 40, 278-295. doi:10.1007/s10964-010-9580-z.

van Roekel, E., Engels, R. C. M. E., Verhagen, M., Goossens, L., \& Scholte, R. H. J. (2011). Parental depressive feelings, parental support, and the serotonin transporter gene as predictors of adolescent depressive feelings: A latent growth curve analysis. Journal of Youth and Adolescence, 40, 453-462. doi: 10.1007/s10964-010-9560-3.

Vrangalova, Z., \& Savin-Williams, R. C. (2011). Adolescent sexuality and positive well-being: A group-norms approach. Journal of Youth and Adolescence, 40, 931-944. doi:10.1007/s10964011-9629-7.

Williford, A. P., Brisson, D., Bender, K. A., Jenson, J. M., \& ForrestBank, S. (2011). Patterns of aggressive behavior and peer victimization from childhood to early adolescence: A latent class analysis. Journal of Youth and Adolescence, 40, 644-655. doi: 10.1007/s10964-010-9583-9.

Zona, K., \& Milan, S. (2011). Gender differences in the longitudinal impact of exposure to violence on mental health in urban youth. Journal of Youth and Adolescence, 40, 1674-1690. doi: 10.1007/s10964-011-9649-3. 